\title{
The Timing of Product Innovation and Regulatory Delay
}

\author{
James E. Prieger ${ }^{1}$ \\ Department of Economics \\ University of California \\ One Shields Avenue \\ Davis, CA 95616-8578 \\ jeprieger@ucdavis.edu
}

September 17, 2001

\footnotetext{
${ }^{1}$ I thank staff members of the telecommunications divisions of the Illinois Commerce Commission, the Indiana Utility Regulatory Commission, the Ohio Public Utilities Commission, and the Wisconsin Public Service Commission. I thank Inho Chung for timely research assistance and seminar participants at UC Davis and the WEAI 75th Annual Conference. The study was supported by a faculty research grant from the University of California, Davis. Some data were obtained from Ameritech for an earlier study while the author was receiving financial support from the company. The views in the paper are not intended to represent those of Ameritech or the state commissions.
} 


\begin{abstract}
This paper endogenizes the interplay between innovation by a regulated firm and regulatory delay. In the signaling model, the firm times its innovation to communicate its private information about the $\mathrm{MC}$ of delay to the regulator. When product innovation costs fall over time, an extra day of regulatory delay increases time to introduction by more than a day. Successful signaling leads the regulator to adjust regulatory delay. The separating equilibrium of the signaling model generates testable predictions for how innovation and regulatory delay evolve over time. The model is consistent with data gathered from one of the Bell telecommunications firms.
\end{abstract}

\title{
PLEASE DO NOT QUOTE WITHOUT PERMISSION
}




\section{Introduction}

The potential for economic regulation to distort the incentives of the firm to innovate is well known (e.g., Sweeney, 1981; Cabral and Riordan, 1989). Most of the literature examining regulation and innovation focuses on the impact of the type of regulatory regime (rate of return vs. incentive regulation, for example) or on the frequency of policy revision (the so-called "regulatory lag"). A little-explored avenue is the effect of regulatory delay on innovation. ${ }^{1}$ Regulatory delay exists when the regulator does not allow the introduction of new products without regulatory review and approval. Regulated firms - for example, in the telecommunications industry - often claim that regulatory delays are long, costly, and distort the incentives to introduce new products. The impacts may also run in the other direction: the firm's innovation decisions may reveal information to the regulator, which might adjust regulatory delay in response. This direction of causality - from firm's innovation to regulator's policy — is neglected in the literature to my knowledge. This paper provides one explanation for changes in regulatory delay and the timing of the firm's innovation. The regulator adjusts delay over time as the firm, through its timing of innovation, reveals information about the cost of delay. The model developd places empirically testable restrictions on the evolution of innovation delay and regulatory delay.

Recent history in the telecommunications industry shows that innovation and regulatory delay change over time. In the data from the beginning of the 1990's from four midwestern states examined here, a given new product tended to be introduced in different areas at different times; by the end of the decade product launches were more likely to be simultaneous. Many state regulatory commissions have modified their policies over time to allow products to reach the market sooner. This pattern also shows up in these data. There are at least three possible explanations for the shift in the firms' and the regulators' behavior. First, perhaps the agents were not choosing the optimal innovation timing and regulatory delay at first, and later they were. Second, it may be

\footnotetext{
${ }^{1}$ Note that "regulatory delay" is a different concept than "regulatory lag". The former refers to delayed introduction of a new product, whereas the latter refers to the term of regulatory commitment.
} 
that the agents were optimizing, but that changing circumstances (i.e., parameters in the objective functions) changed the optimal actions. Third, and most economically interesting, the agents may hold private information, and have adjusted their actions over time in response to information revealed by the other agent. In this paper I focus on this third explanation, by means of a signaling model.

There are regulator-side and firm-side components to the delay between technological feasibility of a product and its introduction to consumers. The regulator-side component is the time between the firm's submission of a new product to the regulator for approval and the granting of approval. I term this component regulatory delay (the term is not intended to be pejorative; delay may have social benefits). The firm-side component is the time between the first technologically feasible introduction date ${ }^{2}$ and the submission of the product to the regulator. I term the firm component innovation delay. While regulation obviously creates regulatory delay, it may also influence innovation delay. Regulatory delay reduces the opportunity cost of innovation delay by pushing the forgone profits from the new product farther into the future. When innovation costs fall over time, regulatory delay thereby induces the firm to postpone innovation.

The regulator trades off the benefit of reducing regulatory delay (quicker return on investment for the firm and earlier accrual of benefits for consumers) and the costs (loss of regulatory control, potentially lower quality of service, harm to competing firms, and the like). The trade-off depends in part on the cost that regulatory delay imposes on the firm, which is likely to be known by the firm better than the regulator. When the firm knows that the regulator would reduce regulatory delay if it knew the true cost of delay to the firm, then the firm would like to communicate its private information to the regulator. The firm can signal its cost of delay with an action that cannot be profitably mimicked by a firm with different cost. A costly action available to the firm is innovation delay. In particular, departures from the myopically optimal length of innovation delay (where "myopic" means decision-making taking regulatory delay as fixed) can serve as signals to

\footnotetext{
${ }^{2}$ I.e., the first date at which the introduction costs are less than infinite.
} 
the regulator.

For innovation delay to serve as a signal, it must be at least partially observable to the regulator. The regulator is not likely to know when products are technologically feasible. If the firm operates in several jurisdictions (e.g., a Bell Operating Company spanning several states), and the firm chooses to introduce new products at differing times in the various jurisdictions, each regulator learns from observing the firm's actions in the other jurisdictions. Once the product is introduced in one area, the regulator in another jurisdiction knows that introduction is technologically feasible. ${ }^{3}$ The firm can then use the time until subsequent submission for approval in the other jurisdictions as a signal.

By jointly modeling the determination of regulatory and innovation delay, this article breaks new ground. The earliest literature on regulation and the timing of innovation looked at a monopolist's incentive to innovate given a fixed regulatory regime (Braeutigam, 1979). More recent work focuses on adoption timing as entry deterrence or accommodation under different regulatory regimes (Riordan, 1992; Lyon and Huang, 1995), but does not explicitly consider regulatory delay. This paper leaves aside rivalry considerations to focus on the relationship between the regulator and the firm. There are a few empirical studies of the impacts of regulatory delay on innovation (Prager, 1989; Prieger, 1999), but these focus on aspects other than asymmetric information and signaling. Spiegel and Wilkie (1996) consider a model in which investment in a new technology has signaling value in a regulated environment, although the receiver of the signal in their model is the capital market, not the regulator.

The model may also apply to other regulatory settings, such as the timing of patenting and patent approval, or of pharmaceutical development and regulatory approval. With minor modifications to the objective functions, the model may also apply to decision-making within a firm, where the agents are the $\mathrm{R} \& \mathrm{D}$ division and management, in place of the firm and the regulator, respectively. In this setting consumer surplus would not enter management's objective function. In

\footnotetext{
${ }^{3}$ As long as the existing infrastructure among the jurisdictions is not too dissimilar. When looking at a single Bell Operating Company, as in my empirical application, this is not likely to be a problem.
} 
each of these settings, there is asymmetric information and the possibility of signaling and learning over time.

The outline of the paper is as follows. In the next section, I introduce a basic model of a firm's decision of when to introduce a new product given the regulatory environment, and then embed the model in a two-period signaling game. Section 3 presents the testable implications derived from the signaling model. Testing of the predictions is carried out in Section 4 with data from a Bell Operating Company. The results show that the signaling model is consistent with the evolution of innovation delay and regulatory delay in all states tested.

\section{The Theoretical Model}

\subsection{A basic model with fixed regulatory delay}

To develop a simple model of regulated product introduction, let time $t=0$ represent the point at which a firm can first feasibly introduce a given product. The firm chooses to submit the product to the regulator for approval at time $s \geq 0$, at which time it incurs fixed development (or adoption) cost $F(s)$. The length of innovation delay $s$ will be referred to as the innovation date. ${ }^{4}$ Following Riordan (1992), fixed costs are assumed to be falling over time as exogenous technological advances lower the cost of adopting the new service: $F^{\prime}(t)<0$ and $F^{\prime \prime}(t)>0$. Falling fixed costs give the firm an incentive to delay innovation. The regulator approves the service after an examination period (i.e., regulatory delay) of length $a$. Consumers cannot purchase and firms cannot sell the good until time $s+a$, referred to as the introduction date. After time $s+a$, the firm earns constant flow profit of $\pi(\theta)$ per unit time, where $\theta \in \Theta \subset \mathbb{R}$ is a parameter known to the firm but not the regulator. ${ }^{5}$ I assume that $\pi^{\prime}(\theta)>0$, so larger $\theta$ might correspond to higher demand or to lower marginal costs. Note that $\pi$ is not an explicit function of price; to focus on the strategic variable

\footnotetext{
${ }^{4}$ Whether $s$ represents true innovation or merely adoption of existing technology (diffusion), the resulting game is the same.

${ }^{5}$ The timing of the model is similar to that of Braeutigam (1979).
} 
$s$ I assume that the firm is allowed by the regulator to charge the profit-maximizing price, ${ }^{6}$ which will be a function of $\theta$. The firm's discount rate is $r$, so that its net present value of introduction at time $s$ is:

$$
\Pi(s, a, \theta)=-e^{-r s} F(s)+\int_{s+a}^{\infty} e^{-r t} \pi(\theta) d t=e^{-r s}\left(-F(s)+e^{-r a} \frac{\pi(\theta)}{r}\right)
$$

The firm chooses optimal innovation date $s^{*}(a, \theta)=\arg \max _{s} \Pi(s, a, \theta)$ which is defined by the first order condition (FOC): ${ }^{7}$

$$
\frac{\partial \Pi(s, a, \theta)}{\partial s}=0 \Rightarrow r F\left(s^{*}\right)-F^{\prime}\left(s^{*}\right)=e^{-r a} \pi(\theta)
$$

The left side of equation (2) is the marginal benefit (MB) from postponing innovation (the reduction in fixed costs), and right side is the marginal cost (MC) of the same (the forgone profit). Thus the firm's private information about $\theta$ can be interpreted as information about the opportunity cost of innovation delay (or, equivalently, of regulatory delay) to the firm.

Given the assumptions of the model, these propositions follow (proofs are in an appendix).

Proposition $1 \partial \Pi / \partial a<0$ and $\partial s^{*} / \partial a>0$. Longer regulatory delay lowers the firm's profit and induces the firm to innovate later.

As regulatory delay increases (e.g., from $a_{L}$ to $a_{H}$ in Figure 1), the forgone profit is pushed farther into the future and its present value, which is the MC of delay, falls. Since MB is decreasing, to re-equate $\mathrm{MC}$ and $\mathrm{MB}$ later innovation dates are chosen by the firm. Thus there is a multiplier associated with regulatory delay: adding a day to $a$ increases $a+s$, the date the service is introduced to consumers, by more than a day.

Proposition $2 \partial s^{*} / \partial \theta<0$. A higher opportunity cost of delay induces the firm to innovate earlier.

\footnotetext{
${ }^{6}$ Many of the new telecommunications services introduced in the data are classed as "competitive" services and are allowed to be freely priced by the firm.

${ }^{7}$ To guarantee $s^{*}>0$, assume $r F(0)-F^{\prime}(0)>e^{-r a} \pi(\theta) \forall \theta$. To guarantee finite $s^{*}$, assume that $\lim _{t \rightarrow \infty} r F(t)-$ $F^{\prime}(t) \leq 0$.
} 
The relevant picture is the same as Figure 1, where now the top MC curve corresponds to a higher $\theta$ and the bottom MC curve corresponds to a lower $\theta$. At first this result might appear counterintuitive; if regulation is "bad for the firm" why would higher regulation-induced costs lead to earlier innovation? The answer is to distinguish between the direct and opportunity costs of regulation. It is the opportunity costs of regulation that $\theta$ measures; as the forgone profit from delay increases, the firm innovates earlier to speed accrual of those profits. If the direct cost of the regulatory process is included as a constant in $F$, then an increase in direct cost would postpone innovation. This can be seen from Figure 1 by shifting the MB of delay curve up.

\section{$2.2 \quad$ A signaling model}

In this section I present a two-period model of innovation and regulation that incorporates the interaction between the firm's choice of innovation date and the regulator's choice of regulatory delay. Stage 1 of the game is the basic model above, where the initial level of regulatory delay, $a_{0} \in \mathbb{R}_{+}$, is predetermined. To present the issues involved, I first discuss a simplified model that highlights the role of signaling. In this first model, the fixed cost $F$ is taken to be constant and nonprohibitive, so that the firm wishes to introduce the product immediately. Thus the only potential value of innovation dates after time 0 is to signal the firm's type. The firm's choice variable is the stage 1 innovation date $s \in \mathbb{R}_{+}$.

In stage 2 , there is another new product opportunity, identical to that in stage 1 . The regulator chooses a new level of delay, $a \in \mathbb{R}_{+}$, then the firm observes $a$ and selects an innovation date $s_{2} \in \mathbb{R}_{+}$for the second new product. The timing of the game allows the firm to signal its type (taken to be fixed over stages) to the regulator in stage 1 to influence the regulatory delay in stage 2. ${ }^{8}$ The assumption of constant fixed cost is relaxed later, in section 2.3.

The players in the game are the following.

\footnotetext{
${ }^{8}$ The game assumes that the regulator cannot commit in stage 1 to a policy $a$ for stage 2 . Lack of commitment is a common assumption in regulatory games (outside of the mechanism design literature). See Spiegel and Spulber (1997) for a discussion of why regulatory commitment is not a realistic assumption.
} 
The firm The firm's profit in each stage is (1), except that now $F(s)$ is constant. It is clear that, absent declining fixed innovation costs and a signaling value to $s$, the optimal $s$ is zero. Total discounted profit is

$$
\Pi_{\text {sum }}\left(s, s_{2}, a_{0}, a, \theta\right)=\Pi\left(s, a_{0}, \theta\right)+\delta \Pi\left(s_{2}, a, \theta\right)
$$

The discount factor $\delta$ is determined from $r$ and the (exogenous) time elapsing between stages (the period of regulatory commitment). For simplicity, take $\Theta \equiv\left\{\theta^{L}, \theta^{H}\right\}, \theta^{L}<\theta^{H}$, so that there are just two types: a low-cost type $L$ and a high-cost type $H$. As above, "cost" here refers to the opportunity cost of regulatory delay and is known only by the firm.

The regulator The regulator's objective function may represent either social welfare (the "benevolent dictator" framework) or the utility function of the regulator (the "economic theory of regulation" approach to regulation (Peltzman, 1976)). Given that $a_{0}$ is predetermined, only stage 2 welfare is relevant. Take expected welfare in stage 2 to be

$$
W\left(s_{2}, a\right)=E_{\theta}\left[C S\left(s_{2}+a, \theta\right)+\Pi\left(s_{2}, a, \theta\right)+V(a)\right]
$$

$E_{\theta}$ represents expectation taken with respect to the regulator's posterior beliefs $b$ about the firm's type. $C S(t, \theta)$ is net consumers' surplus when the product is introduced at time $t$ and the firm's type is $\theta$. I assume $\partial C S / \partial t<0, \partial C S / \partial \theta \geq 0, \partial^{2} C S / \partial t^{2} \geq 0$, and $\partial^{2} C S / \partial t \partial \theta \leq 0 .{ }^{9}$ The firm's type affects $C S$ at least indirectly because the monopoly prices charged are a function of $\theta$. If $\theta$ represents a demand parameter, then $\theta$ will also have a direct impact on $C S$. $V$ is the benefit to the regulator from regulatory delay, with $V^{\prime}>0$.

The interpretation of $V$ varies with the interpretation of the regulator's objective. In a benevolent dictator setting, $V$ may represent benefits not reflected in $C S$ from higher quality or lower level of externalities that may result from regulatory delay. ${ }^{10}$ In a political economy setting, $V$

\footnotetext{
${ }^{9}$ These assumptions are consistent with $c s$ being the discounted present value of a constant surplus flow $\alpha(\theta)$. For example, if $c s=\exp (-r[s+a]) \alpha / r$, then as long as $\partial c s / \partial \theta \geq 0$, the other assumptions follow.

${ }^{10}$ If delay represents the time taken by the firm to bring the product up to a regulatory quality standard, then longer delays may increase product quality. If delay represents time taken by the regulator to investigate safety or privacy concerns (e.g., caller ID or caller ID blocking), then longer delays may decrease externalities.
} 
might represent payoffs (direct or indirect) to the regulator from the firm's rivals or a preference for exercising authority.

Solution concept The relevant solution concept in this Spence-type signaling game is perfect Bayesian equilibrium (PBE). ${ }^{11} \mathrm{~A}$ PBE consists of the firm's strategies $s_{1}^{*}\left(a_{0}, \theta\right)$ for $s$ and $s_{2}^{*}(a, \theta)$ for $s_{2}$, a strategy $a^{*}(s)$ for the regulator, and the regulator's posterior beliefs $b(s)$ about the probability after observing $s$ that $\theta=\theta_{L}$, such that

- $\left(s_{1}^{*}(a, \theta), s_{2}^{*}(a, \theta)\right)$ maximizes $\Pi_{\text {sum }}\left(s, s_{2}, a_{0}, a, \theta\right)$ given the firm's correct expectation that $a=$ $a^{*}(s)$,

- $a^{*}(s)$ maximizes $W\left(s_{2}, a\right)$ given the posterior beliefs and the regulator's correct expectation that $s_{2}=s_{2}^{*}(a, \theta)$, and

- the beliefs $b(s)$ are derived from Bayes' rule whenever possible. ${ }^{12}$

Note that the strategic variables of interest are $s$, the signal by the firm in stage 1 , and $a$, the response by the regulator in stage 2 . There will be no strategic considerations in the firm's choice of $s_{2}$, since it is the last move in the game. I restrict my focus to cases of successful signaling: separating equilibria. As is well-known in signaling games, the PBE may admit too many "unrealistic" equilibria because it does not restrict beliefs off the equilibrium path. Multiple equilibria do not complicate testing the theory empirically, because in section 2.3 I show that all separating equilibria share certain testable characteristics.

The regulator's strategy Because the PBE is sequentially rational, we may use backward induction to solve the game. In the final move of the game, the firm chooses $s_{2}^{*}=0$ no matter

\footnotetext{
${ }^{11}$ I restrict attention to pure (non-random) strategies.

${ }^{12}$ In particular, on the equilibrium path, $b=1$ if $\theta=\theta_{L}$ in a screening equilibrium (the regulator learns the firm's true type) and $b$ cannot be updated in a pooling equilibrium (the regulator retains its prior beliefs when it receives an uninformative signal). Bayes' rule does not apply off the equilibrium path, since there is no probability of ending up there.
} 
what $\theta$ or $a^{*}$ is; with constant fixed costs, the firm always prefers immediate innovation. Given that $s_{2}^{*}=0$ and that stage 1 actions are bygones, the regulator will choose $a^{*}$ as

$$
a^{*}(s)=\arg \max _{a}\left[W\left(s_{2}^{*}=0, a\right) \mid b(s)\right]
$$

the stage 2 welfare maximizing choice given the posterior beliefs after observing signal $s$ from the firm. If $a^{*}>0$ and $W$ is continuous in $a$, the optimal choice of regulatory delay thus satisfies

$$
\left.\left[\frac{\partial}{\partial a} W\left(s_{2}^{*}(a, \theta), a\right) \mid b(s)\right)\right]=0
$$

Ignoring the expectation operator in (4) for the moment, the FOC is

$$
V^{\prime}\left(a^{*}\right)=-\left[\frac{\partial C S\left(a^{*}, \theta\right)}{\partial t}+\frac{\partial \Pi\left(0, a^{*}, \theta\right)}{\partial a}\right]
$$

Only the direct effect of $a$ on $\Pi$ need be considered, since $s_{2}^{*}$ does not change with $a$. The term on the left side is the MB of delay for the regulator. The right side terms compose the regulator's MC of delay, which is equal to the MB at $a^{*}$.

Of central interest for characterizing a separating equilibrium is how $a^{*}$ changes with $\theta$. Some additional notation will be useful. Let $a^{H}$ and $a^{L}$ be the optimal regulatory delay in stage 2 when the regulator knows that the firm's type is $\theta^{L}$ and $\theta^{H}$, respectively. Whether $a^{L}$ is larger than $a^{H}$ cannot be determined in general. The reason, made precise in the appendix, is as follows. If $V$ is assumed concave, the MB of delay for the regulator is decreasing in $a$. However, the MC of delay for the regulator is also decreasing in $a$. The $\mathrm{MC}$ curve when the firm is type $H$ is above the MC curve when the firm is type $L$, given the assumptions in the model. Which downward-sloping MC curve intersects with the downward-sloping MB curve at the smallest $a$ therefore depends on relative slopes of the MB and MC curves. The assumptions of the model do not say which curve is steeper. Thus the optimal regulatory delay could either be increasing or decreasing in the firm's type, and the sign of $a^{L}-a^{H}$ is indeterminate. I develop results for both cases.

Consider the outcome of a separating equilibrium. Assume that the predetermined $a_{0}$ is between $a^{L}$ and $a^{H} .{ }^{13}$ Since the sign of $a^{L}-a^{H}$ is ambiguous, the sign of $a^{*}-a_{0}$ is also ambiguous in

\footnotetext{
${ }^{13}$ As it would be, for example, if $a^{*}$ is monotone in $\theta$ and $a_{0}$ is stage-optimal given the prior beliefs of the regulator.
} 
general, even if the firm's type is known. If $a^{L}<a^{H}$, then the low cost type wants to signal its type to bring about a reduction in $a$. If $a^{L}>a^{H}$, then the high cost type wants to signal its type to bring about a reduction in $a$.

The firm's strategy Looking ahead to $a^{*}(s)$, the regulator's policy, the firm wishes to signal its type when doing so will cause the regulator to reduce regulatory delay from $a_{0}$. Take first the case where $a^{L}<a^{H}$. The low cost type $L$ has an incentive to signal its type to receive $a^{L}$ rather than $a^{H}$, since lower $a$ is always better for the firm. Since both types would set $s=0$ to myopically maximize stage profit, the low cost type "burns money" to signal by setting an $s>0$. Denote $L$ 's signal by $s^{L} .{ }^{14}$ For the signal to be part of a separating equilibrium, signaling must be costlier for $H$ than for $L$. First, the high cost firm must find it less profitable to send signal $s^{L}$ to induce $a^{L}$ than to send 0 , which induces $a^{H}$ :

$$
\begin{gathered}
\Pi_{\text {sum }}\left(s^{L}, 0, a_{0}, a^{L}, \theta^{H}\right) \leq \Pi_{\text {sum }}\left(s_{1}^{H}, 0, a_{0}, a^{H}, \theta^{H}\right) \quad \Rightarrow \\
\text { IC1: } \quad \delta\left[\Pi\left(0, a^{L}, \theta^{H}\right)-\Pi\left(0, a^{H}, \theta^{H}\right)\right] \leq\left[\Pi\left(0, a_{0}, \theta^{H}\right)-\Pi\left(s^{L}, a_{0}, \theta^{H}\right)\right]
\end{gathered}
$$

Both sides are positive: the left side is the second period gain from fooling the regulator into believing the firm is low cost, and the right side is the first period gain from not doing so. This incentive constraint places a lower bound on $s^{L}$ : if $s^{L}$ is too low the high-cost type will not find the signal too costly to mimic.

The other incentive constraint is for the low cost type. The signal $s^{L}$ must be such that the gain from signaling reaped in stage 2 outweighs the lost profit in stage 1:

$$
\text { IC2: } \delta\left[\Pi\left(0, a^{L}, \theta^{L}\right)-\Pi\left(0, a^{H}, \theta^{L}\right)\right] \geq\left[\Pi\left(s_{1}^{L}, a_{0}, \theta^{L}\right)-\Pi\left(s^{L}, a_{0}, \theta^{L}\right)\right]
$$

This incentive constraint places an upper bound on $s^{L}$ : if it is too high $L$ will find the signal too costly to send.

\footnotetext{
${ }^{14}$ For ease of presentation, the incentive compatibility constraints are written as if the set of possible low cost signals is a singleton. This would be so for the case where the regulator has "pessimistic beliefs": unless it receives signal $s^{L}$, it assumes the firm is type $H$. The argument does not change materially if the regulator accepts signals from a set of possible values.
} 
As long as the upper bound on the signal $s^{L}$ (defined by equality in IC2) is above its lower bound (defined by equality in IC1), a separating equilibrium exists. ${ }^{15}$ The appendix proves existence for this model.

Figure 2 depicts a PBE when $a^{L}<a^{H}$. In the figure, profit increases toward the origin because both $a$ and $s$ are costly to the firm. IC1 is depicted by the isoprofit curve for $H$ that goes through point $\left(0, a^{H}\right) \cdot{ }^{16}$ The profit for $H$ from sending the signal $s^{L}$ and receiving $a^{L}$ in return must be lower than the profit from the myopically optimal $s=0$ and receiving $a^{H}$ in return. Signals to the right of $s^{L}$, where this isoprofit curve crosses the $a^{L}$ dotted line, satisfy this condition. The heavy dashed line represents a possible strategy for the regulator that supports a PBE. The regulator here use a threshold strategy: any signal below $s^{L}$ results in belief $b=0$ and action $a^{H}$, and any signal at or above $s^{L}$ results in belief $b=1$ and action $a^{L} \cdot{ }^{17}$ Given the regulator's strategy, $L$ does best to send signal $s^{L}$ and $H$ does (weakly) best to send $s=0$. Any other signals put each type on an isoprofit curve further to the northeast in the figure, which represents lower profit. Note that this particular regulatory policy induces the lowest-cost signal from $L$.

Now consider the case where $a^{L}>a^{H}$. Type $H$ would like to signal its type. However, because signaling is less costly for the low cost type, no separating equilibrium can exist. The results from both cases are summarized in the following proposition.

Proposition 3 In the signaling model with constant fixed costs, if $a^{L}<a^{H}$ a separating equilibrium exists. Type $L$ signals with $s>0$ and receives $a<a_{0}$ in stage 2 as a result. The type $H$ sets $s=0$ and receives $a>a_{0}$ in stage 2 as a result.

\footnotetext{
${ }^{15}$ The intuitive criterion (Cho and Kreps, 1987) can be invoked to eliminate all separating equilibria except the unique Pareto-dominating one, which has the least-costly signal (the lower bound defined by IC1). The empirical predictions from the model do not depend on whether the separating equilibrium is the Pareto-dominating one.

${ }^{16}$ The isoprofit curves shown in $(s, a)$ space assume that $s_{2}=s_{2}^{*}(a)$. The appendix shows that the isoprofit curves have the convex shape shown in figure 2 .

${ }^{17}$ Many other strategies for the regulator would also support this separating equilibrium, as long as the heavy dashed line in figure 2 is between $a^{L}$ and $a^{H}$, above both isoprofit curves, and passes through $\left(s^{L}, a^{L}\right)$.
} 


\subsection{Extending the signaling model: time-varying fixed costs}

In dynamic industries such as telecommunications, it is more realistic to assume that the fixed costs of innovation are not constant but are falling over time. With this extension, a separating equilibrium may exist even if $a^{L}>a^{H}$, unlike the constant fixed cost case. Consider the model from section 2.2 but with the declining fixed costs from section 2.1. The sign of $a^{L}-a^{H}$ is still indeterminate (see the appendix). An added complication when innovation costs are falling is that the isoprofit curves are no longer monotonic in $(a, s)$ space. However, it is still true that in any separating equilibrium, type $L$ signals with a higher $s$ than type $H$ when $a^{L}<a^{H}$, and vice-versa (given a single-crossing condition) when $a^{H}<a^{L}$.

Figure 3 depicts the isoprofit curves representing the two incentive compatibility constraints. Lower isoprofit curves represent higher levels of profit. As before, IC1 prevents signal $s^{L}$ (which results in $a^{L}$ ) from giving more profit to $H$ than does $s_{1}^{H}=s_{1}^{*}\left(a_{0}, \theta^{H}\right)$ (which results in $\left.a^{H}\right)$. The relevant isoprofit curve for $H$ is the one passing through the point $\left(s_{1}^{H}, a^{H}\right)$, and IC1 excludes $L$ 's signal from being between $A$ and $C$ on the graph. IC2 prevents $L$ 's signal from giving less profit to $L$ than does $s_{1}^{L}$, the stage-optimal $s$. The relevant isoprofit curve for $L$ is the one passing through the point $\left(s_{1}^{L}, a^{H}\right)$, and IC2 restricts $L$ 's signal to be between $B$ and $D$ on the graph. Thus an incentive compatible separating equilibrium requires $L$ 's signal to be between $C$ and $D$. Figure 4 shows one possible separating equilibrium. In the figure, the signal $s^{L}$ is the least costly incentivecompatible signal. The regulator uses a threshold strategy (the heavy dashed line) to support equilibrium in this case: any signal below $s^{L}$ results in $a^{H}$, and any signal at or above $s^{L}$ results in $a^{L} .{ }^{18}$ Given the regulator's strategy, $L$ does best to send signal $s^{L}$ and $H$ does (weakly) best to send $s_{1}^{H}$. The appendix shows that when $a^{L}<a^{H}$, any separating equilibrium has $L$ sending a larger signal $s$ than $H$ sends. Consequently, it is always the case that $s^{L} \geq s_{1}^{L}>s_{1}^{H}$.

When $a^{H}<a^{L}$ instead, then the separating equilibrium has $H$ signaling with a low $s$ (see

\footnotetext{
${ }^{18}$ Other strategies for the regulator would also support this separating equilibrium; see footnote 17.
} 
Figure 5 for one possible equilibrium and the appendix for details). In this case, the firm innovates quicker than would be stage optimal, to signal that delays have a high cost to the firm.

The results for the model with time-varying fixed costs are summarized in the following propositions.

Proposition 4 In the signaling model with time-varying fixed costs, if a separating equilibrium exists, then:

- when $a^{L}<a^{H}$, type $L$ signals with $s^{L} \geq s_{1}^{L}$ in stage 1 , and the regulator sets $a<a_{0}$ and $L$ chooses $s_{2}<s^{L}$ in stage 2 ;

- when $a^{L}<a^{H}$, type $H$ chooses $s_{1}^{H}$ in stage 1 , and the regulator sets $a>a_{0}$ and $H$ chooses $s_{2}>s_{1}^{H}$ in stage 2 ;

- when $a^{L}>a^{H}$, type $H$ signals with $s^{H} \leq s_{1}^{H}$ in stage 1 , and the regulator sets $a<a_{0}$ and $H$ chooses $s_{2}$ which may be larger or smaller than $s_{1}^{H}$ in stage 2;

- when $a^{L}>a^{H}$, type $L$ chooses $s_{1}^{L}$ in stage 1 , and the regulator sets $a>a_{0}$ and $L$ chooses $s_{2}>s_{1}^{L}$ in stage 2.

The results in Proposition 4 concerning $\Delta s \equiv s_{2}-s$ follow from Proposition 1, which shows that the stage-optimal $s$ increases with $a$. In the third bullet point, $\Delta s$ is indeterminate: although the decrease in $a$ will ensure that $s_{2}<s_{1}^{H}$, the stage 1 signal also may be below $s_{1}^{H}$ to meet IC2 for $H$.

\section{Empirical Predictions and Data}

The theoretical model generates predictions for the evolution of innovation and regulatory delay. The results from the signaling model in section 2.3 depend on whether $a^{H}$ is greater than $a^{L}$, which in turn depends on second derivative of $V$. An observer (i.e., the econometrician) will not know 
if $a^{H}$ is greater than $a^{L}$ if the parameters and functional forms in the game are unknown. What restrictions does the theory place on observed behavior without this knowledge? Proposition 4 implies the following. For type $L$ one would observe $s$ and $a$ decreasing from stage 1 to stage 2 (the case when $a^{L}<a^{H}$ ), or $s$ and $a$ increasing (the case when $a^{L}>a^{H}$ ). In short, the signs of $\Delta s$ and $\Delta a$ are equal, and an opposite finding would reject the model. For type $H$ one would observe $s$ and $a$ increasing (the case when $a^{L}<a^{H}$ ), or $a$ decreasing and an indeterminate change in $s$ (the case when $a^{L}>a^{H}$ ). If type is not known, then the only pattern of changes that would reject the model is $\Delta s<0<\Delta a$. Such a test is non-parametric, in the sense that it depends only on $\Delta s$ and $\Delta a$, and no functional forms need be assumed for $p i, C S$, or $V$. The implications of the model are summarized in Table 1.

Note that the model required that the profit, cost, and consumers' surplus functions were the same in both stages. In the empirical application, then, I control for variables that affect these (size, density, and wealth of the market, etc.). Controlling for difference in profit, cost, and consumers' surplus isolates the impact of regulatory delay on innovation.

Data were collected on innovation and introduction dates for new telecommunications services offered by Ameritech in four of its state jurisdictions: Illinois, Indiana, Ohio, and Wisconsin. ${ }^{19}$ Ameritech, one of the Bell regional holding companies, is the dominant local exchange company in each of these states, and its intrastate activities are regulated by the state commissions. Introduction of a new service required petitioning the state regulator; the service could not be offered to subscribers until regulatory approval was granted. Examples of the residential and business services in the data are new voice mail features, virtual networking services, and high-speed transmission services. The data cover the span 1991 through 1999, which comprises three regulatory periods. ${ }^{20}$ In the first period, 1991 through mid 1994, Ameritech was under some form of rate of return regulation in each state. Following this first period, each state switched to some form of

\footnotetext{
${ }^{19}$ The data are from the tariff filing logs of the company and the state commissions. Supplemental information was culled from the actual state tariffs where needed.

${ }^{20}$ The data for Ohio are complete only for years 1994-1999.
} 
incentive regulation. After three years of the new regulation, in 1997 the regimes were reviewed in at least some of these states. ${ }^{21}$ Thus the regulators had three opportunities to change their regulatory delay policy (i.e., to change $a$ ). Preliminary statistical work revealed that the latter two periods were indistinguishable in terms of average $a$ and $s$, and so I take stage one of the game to correspond to the first period and stage two of the game to correspond to the latter two periods.

The first difficulty for the empirical investigation is how to measure $s$, time between potential and actual innovation ("innovation delay"). I take the date at which a service is first introduced in any of these states to be $t=0$, and then measure $s$ for the other states relative to the first state's innovation date. ${ }^{22}$ This effectively underestimates true innovation delay: the true time 0 must be weakly before the observed first "innovation" under this definition. However, this measurement corresponds to the portion of innovation delay that the regulator actually observes, which is the only useful part for signaling, and therefore is a good measurement of $s$ as used in the model. To apply the single-firm single-regulator theoretical model from the previous section, it is assumed that there are no strategic effects among jurisdictions. To be included in the data set, a new service had to be introduced in at least two states. One hundred fourteen services were introduced in at least two states, generating 349 observations. Summary statistics for the observations on $s$ are in Table 2. Regulatory delay, $a$, is measured as the time from the first tariff filing submission date to the approval date of the last tariff filing for the service. ${ }^{23}$ Summary statistics for $a$ are in Table 3.

\section{The Empirical Tests}

The goal of the empirical work is to test the predictions from the signaling model summarized in Table 1. To this end, I calculate $\Delta s, \Delta a$, and attempt to infer the type of the firm where it matters

\footnotetext{
${ }^{21}$ See Roycroft (1999) for more information on the regulatory regimes.

${ }^{22}$ Some access services were introduced in the federal access tariff before in any of the state tariffs. In such cases $s$ is calculated using the federal access tariff filing date as $t=0$ (and an indicator for these observations, FAT, is used in the statistical work).

${ }^{23}$ Some services had multiple tariff filings and withdrawals before approval was granted. Regulatory delay data is not available for Ohio.
} 
for the tests.

Estimating the change in innovation delay From the raw data in Table 3 it appears that innovation delay dropped substantially from stage 1 to stage 2 . I estimate the entire distribution of innovation delay in the states in the two stages via a nonparametric method (Figure 8). ${ }^{24}$ The figure presents the survival curves (defined to be $1-C D F$ ) and reveals convincing evidence that stage $2 s$ stochastically dominates stage $1 s$. Estimated means and medians from the curves are in Table 4, and confirm the visual evidence from the curves: the mean and median innovation delay is smaller in each state in stage 2. Although the confidence intervals for the medians are non-overlapping only in Indiana and Wisconsin, if a slightly higher quantile is chosen, e.g. the 0.6 quantile (which corresponds to the ordinate 0.4 on the survival curves), the confidence intervals are non-overlapping in all states. Thus it appears that $\Delta s<0$ in each state.

Since the nonparametric method does not allow covariates, I turn next to a semiparametric model to control for economic conditions and other factors that may change over time and influence the firm's behavior apart from the strategic considerations that I want to isolate. Estimates from a Cox proportional hazards model are in Table 5. In the Cox model, the hazard rate of the innovation delay durations is

$$
\lambda\left(t, \mathbf{x}_{i}^{\prime}\right)=\exp \left[-\left(\mathbf{x}_{i}^{\prime} \boldsymbol{\beta}\right)\right] \lambda_{0}(t),
$$

where $\lambda_{0}$ is an arbitrary, unspecified baseline hazard and $\mathbf{x}_{i}$ is a vector of covariates for spell $i^{25}$ Positive coefficients for $\boldsymbol{\beta}$ decrease the hazard and therefore increase mean duration. The first estimation replicates the finding from the survival curve estimation. When only fixed effects are included - state dummies (IN, OH, WI), state-specific indicators for stage 2 (STATE:reg change), and the federal tariff dummy (FAT, see note 22) - the coefficients for the regulatory change all indicate shorter delay times in stage 2 (see the first columns of Table 5). This finding generally

\footnotetext{
${ }^{24}$ The estimates are from Turnbull's (1974) generalization of the Kaplan-Meier (Kalbfleisch and Prentice, 1980) method.

${ }^{25}$ The Cox $(1972 ; 1975)$ model uses a $\sqrt{N}$-consistent partial likelihood method to estimate $\boldsymbol{\beta}$.
} 
persists when economic covariates are added, such as per capita income (PCI), the number of access lines in each state (a measure of market size) (ACCESS), population density (denser areas are cheaper to serve per subscriber due to technologies economies) (DENSITY), and (lagged) industry telecom patents ${ }^{26}$ (INDPAT $\left.T_{t-1}\right)$. These covariates are allowed to evolve over the course of a duration. Adding these variables does not remove the conclusion that $\Delta s<0$ except for Illinois, for which the coefficient loses significance. Formally, one cannot reject the hypothesis that $\Delta s>0$ in Illinois at the $5 \%$ level. Taken together, then, the evidence from all estimations indicates that $\Delta s<0$, except possibly in Illinois.

Estimating the change in regulatory delay Evidence on the change in regulatory delay between the two periods comes from several sources. The first evidence comes from the institutional changes that took place in 1994. In each state, expedited approval for new services received special attention in the new incentive regulation plans. In Illinois, new services deemed competitive were allowed to be introduced on one day's notice, and many more services were classified as competitive after the regulatory change. In Indiana, all new services were allowed to be introduced on one day's notice, down from at least a month of regulatory delay before the new plan. In Ohio, competitive services were effectively detariffed and allowed to be introduced with essentially no regulatory scrutiny. In Wisconsin, approval for most new services was to be granted after 10 days unless suspended for investigation, down from about a month under rate of return regulation. The intent of the new regulation was to ensure that $\Delta a<0$.

Another source of evidence is to examine the data themselves. Table 3 shows that the mean and median tariff approval delay dropped in Illinois, Indiana, and Wisconsin (no data are available for Ohio), so it appears that $\Delta a<0$. Estimation results lead to similar conclusions. The survival curves for the regulatory delay data (Figure 9) indicate that stage 2 a stochastically dominates stage 1 a. Estimated means and medians from the curves are in Table 6: the estimated mean

\footnotetext{
${ }^{26}$ The Bell Operating Companies take out few patents themselves, and typically create new services from underlying technology patented by others.
} 
and median regulatory delay is smaller in each state in stage 2 . The confidence intervals for the medians are non-overlapping in all states.

Similarly, in a Cox estimation (Table 7), the coefficients indicate statistically significant shorter regulatory delay time in each state in stage 2 . When covariates are included instead of state fixed effects, all three states still show shorter regulatory delay time in stage 2 , but the coefficient for Illinois loses significance. The included covariates are political economy variables used in other studies of regulatory change (Donald and Sappington, 1997): the log annual budget of the regulatory authority (PUCBUDGET), an indicator for Republican control of both houses of the state legislature and a Republican governor (REPUB), and the average value of REPUB from 1984 up to the previous year. ${ }^{27}$ Taken together, the evidence from all estimations indicates that $\Delta a<0$, except possibly in Illinois.

The test results From the evidence and estimations above it appears that for all states except possibly Illinois, we have case 1 from Table 1: $\Delta s<0$ and $\Delta a<0$. Even without knowledge of type, these patterns are consistent with the signaling model. To reject the signaling model, it is necessary that $\Delta s$ and $\Delta a$ have opposite signs. The statistical evidence shows that this is not the case in Indiana and Wisconsin. A combination of statistical evidence (for $\Delta s$ ) and institutional evidence (for $\Delta a$ ) suggests that this is also not the case in Ohio. Thus the signaling model is consistent with the evolution of innovation delay and regulatory delay in these three states.

For Illinois, the negative coefficients on $\Delta s$ and $\Delta a$ are not significant in all estimations, so we cannot immediately reject the possibility that we have case 2,3 , or 4 from Table 1 . Consider these cases in turn. Case 2 poses no problem for the signaling model; it is consisten with the theory. Case 3 is consistent with the model only if the firm is type $H$.

Can anything be inferred from the data, then, about the firm's type in Illinois? Once one controls for differences across states, then within a stage the difference in (average) $s$ across states

\footnotetext{
${ }^{27}$ The other political economy variable used in Donald and Sappington (1997), an indicator for elected public utility commissioners, can not be used here because commissioners are not elected in any state.
} 
will be driven by differences in $\theta$. So in an estimation that controls for differences in the profit opportunities among states, any residual fixed effects for the states would give information about $\theta$. In particular, if both types are present in the data, then the state with the largest negative fixed effect, and therefore the shortest innovation delay after controlling for profitability, is type $H$. This follows from Proposition 2; type $H$ firms will have shorter innovation delay than type $L$ firms. Controls for profitability include economic and demographic covariates such as those used in the innovation delay estimation above, and also expected regulatory delay. ${ }^{28}$ The estimation results are in the final column of Table 5. The estimated fixed effect for IL (coefficient $I L$ in the table) is the largest negative state fixed effect. Therefore, if the firm is type $H$ anywhere, it is in Illinois. If the firm is type $H$ in Illinois, then Case 3 does not reject the signaling model.

Case 4 rejects the model regardless of the firm's type. To formally test the hypothesis that $\Delta s<0$ and $\Delta a>0$, I applied Wolak's (1991) testing methodology for inequality constraints in non-linear models. The $p$-value from the test using the "IL:reg change" coefficients from the fixed effects models is 0.10 . The $p$-value from the test using the coefficients from the covariate models is $0.36 .^{29}$ Neither test convincingly rejects the Case 4 hypothesis. For Illinois, then, we are left with institutional, nonparametric, and semiparametric evidence that Case 1 applies, but also with semiparametric inference too weak to reject that Case 4 might apply.

\section{Conclusion and Further Directions}

This paper presents a model that endogenizes innovation timing and regulatory delay. The firm uses the timing of new product introduction to signal the marginal cost of regulatory delay to the regulator. In a separating equilibrium, the regulator responds to the revealed information by

\footnotetext{
${ }^{28}$ The variable measuring expected regulatory delay for each observation is constructed assuming the firm believes regulatory delay is exponentially distributed (with rate $\lambda$ ). The expectation is calculated given observed completed and ongoing delays with Bayesian updating. The prior distribution for $\lambda$ is taken to be Gamma (the conjugate prior). Regulatory delay data is not available for Ohio and those observations are dropped.

${ }^{29}$ In neither the innovation delay nor the regulatory delay estimations can a preferred model be selected (between the fixed effects and covariates versions); Vuong's (1989) test for non-nested model selection indicates that neither is preferred to the other.
} 
adjusting regulatory delay. The model generates testable predictions, which are not rejected by data gathered from a Bell Operating Company's operations in four states. The evidence for one of the states, however, is mixed.

Of course, the empirical evidence does not rule out all other explanations for the observed evolution of innovation and regulatory delay. However, external evidence on the changing attitudes of regulators supports the model. Over the last decade, regulatory commissions (in some cases prodded by state legislatures) have placed more emphasis on the benefits from new products. The older breed of regulatory official, accustomed to tight regulatory control and a stable industry, viewed new products with suspicion. As one regulator put it, "...regulation of telecommunications remain essential to protect the public from deleterious consequences of innovation..." (Oppenheim, 1991, p.310). Contrast this view with the more recent goals adopted by regulators in the Ameritech region to "...facilitate the introduction of innovative new services in this competitive marketplace." (PSC of Wisconsin, 1998, p.47) This change of attitude about the importance of new products to consumers and firms corresponds to the case in the model in which the regulator learns that the MC of delay is high. In that case (Case 1) the model shows that both innovation and regulatory delay fall over time, which is exactly what happens in the data.

There are two interesting extensions to the model that deserve future attention. First, in the current formulation actions undertaken in one jurisdiction have no signaling value to regulators in the other jurisdictions (apart from alerting regulators that a certain service is technologically feasible after it is introduced in the first state), and the firm's decision is taken to be independent across states. A logical next step for the model is to expand the signaling game to include multiple receivers of the firm's multiple signals. Whether such a model will generate predictions restrictive enough to falsify the model remains to be seen.

Another extension would be to explicitly incorporate unregulated rivals into the model. The only impact of competition in the current model is indirect: it may affect the MC of delay to the firm $(\theta)$ or the regulator's benefits of delay $(V)$. Given that local telecommunications competition 
was just getting off the ground during the period studied, including competition in the model seems to be most useful for application to future data sets.

\section{References}

Braeutigam, Ronald R. (1979), 'The Effect of Uncertainty in Regulatory Delay on the Rate of Innovation', Law and Contemporary Problems 43(3), 98-111.

Cabral, Luis M. B. and Riordan, Michael H. (1989), 'Incentives for Cost Reduction Under Price Cap Regulation', Journal of Regulatory Economics 1(2), 93-102.

Cho, In-Koo and Kreps, David M. (1987), 'Signaling Games and Stable Equilibria', Quarterly Journal of Economics 102, 179-221.

Cox, David R. (1972), 'Regression Models and Life-Tables', Journal of the Royal Statistical Society, Series B 34, 187-202.

Cox, David R. (1975), 'Partial Likelihood', Biometrika 62, 269-276.

Donald, Stephen G. and Sappington, David E. M. (1997), 'Choosing Among Regulatory Options in the United States Telecommunications Industry', Journal of Regulatory Economics 12(3), 227243.

Kalbfleisch, John D. and Prentice, Ross L. (1980), The Statistical Analysis of Failure Time Data, Wiley Series in Probability and Mathematical Statistics, New York: John Wiley \& Sons.

Lyon, Thomas P. and Huang, Haizou (1995), 'Asymmetric Regulation and Incentives for Innovation', Industrial and Corporate Change 4(4), 769-776.

Oppenheim, Jerrold (1991), in B. G. Cole, ed., 'After the Breakup: Assessing the New Post-AT\&T Divestiture Era', Columbia Univ. Press, p. $310 f f$. 
Peltzman, Samuel (1976), 'Toward a More General Theory of Regulation', Journal of Law and Economics 19, 211-240.

Prager, Robin A. (1989), 'The Effects of Regulatory Policies on the Cost of Debt for Electric Utilities: An Empirical Investigation', Journal of Business 62(1), 33-53.

Prieger, James E. (1999), Regulation, Innovation, and the Introduction of New Telecommunications Services, PhD thesis, University of California, Berkeley.

Public Service Commission of Wisconsin (1998), 'Staff Report on Telecommunications Utility Price Regulation', November. Docket 05-TI-174.

Riordan, Michael H. (1992), 'Regulation and Preemptive Technology Adoption', RAND Journal of Economics 23(3), 334-349.

Roycroft, Trevor R. (1999), 'Alternative Regulation and the Efficiency of Local Exchange Carriers: Evidence From the Ameritech States', Telecommunications Policy 23, 469-480.

Spiegel, Yossef and Spulber, Daniel F. (1997), 'Capital Structure with Countervailing Incentives', RAND Journal of Economics 28(1), 1-24.

Spiegel, Yossef and Wilkie, Simon (1996), 'Investment in a New Technology as a Signal of Firm Value under Regulatory Opportunism', Journal of Economics and Management Strategy $\mathbf{5}(2), 251-276$.

Sweeney, George (1981), ‘Adoption of Cost-Saving Innovations by a Regulated Firm', American Economic Review 71(3), 437-447.

Turnbull, Bruce W. (1974), 'Nonparametric Estimation of a Survivorship Function with Doubly Censored Data', Journal of the American Statistical Association 69, 169-173.

Vuong, Quang H. (1989), 'Likelihood Ratio Tests for Model Selection and Non-Nested Hypotheses', Econometrica 57(2), 307-333, March. 
Wolak, Frank A. (1991), 'The Local Nature of Hypothesis Tests Involving Inequality Constraints in Nonlinear Models', Econometrica 59(4), 981-995.

\section{Appendix}

Proof of Proposition 1 First, from (1), $\partial \Pi / \partial a=-e^{-r a} \pi(\theta)<0$. Second, letting $s^{*}(a, \theta)=$ $\arg \max \Pi(s, a, \theta)$, we can find $\partial s^{*} / \partial a$ by differentiation of $(2)$, since (2) holds for all $a$ : $\frac{\partial s^{*}}{\partial a}=$ $\frac{r e^{-r a} \pi(\theta)}{F^{\prime \prime}\left(s^{*}\right)-r F^{\prime}\left(s^{*}\right)}>0$, where the inequality follows from the assumptions on $F$ (i.e., $F^{\prime}<0$ and $F^{\prime \prime}>0$.

Proof of Proposition 2 The marginal cost of delay to the firm is the same whether the delay stems from the firm's or the regulator's choice. We can find $\partial s^{*} / \partial \theta$ by differentiation of $(2)$, since (2) holds for all $\theta$ : $\frac{\partial s^{*}}{\partial \theta}=-\frac{e^{-r a} \pi^{\prime}(\theta)}{F^{\prime \prime}\left(s^{*}\right)-r F^{\prime}\left(s^{*}\right)}<0$, where the inequality follows from the assumptions on $F$.

Is $a^{L}<a^{H}$ ? Assume for the moment that the firm's type is known (as it will be in a separating equilibrium), so that (7) represents the first-order condition for the welfare-maximizing $a$. Then the impact of a marginal change in type on the regulator's choice of delay may be found by differentiating (7), since (7) holds for all $\theta$. Integrating the resulting $d a^{*} / d \theta$ over the discrete change in type from $\theta^{L}$ to $\theta^{H}$ tells us whether $a^{L}<a^{H}$ or vice versa. The derivative of (7) with respect to $\theta$ is:

$$
\begin{gathered}
\left(\frac{\partial^{2} C S}{\partial t^{2}} \frac{d a}{d \theta}+\frac{\partial^{2} C S}{\partial t \partial \theta}\right)+V^{\prime \prime}(a) \frac{d a}{d \theta}+\left(\frac{\partial^{2} \Pi}{\partial a^{2}} \frac{d a}{d \theta}+\frac{\partial^{2} \Pi}{\partial a \partial \theta}\right)=0 \\
\Rightarrow \frac{d a^{*}}{d \theta}=-\frac{\frac{\partial^{2} C S}{\partial t \partial \theta}+\frac{\partial^{2} \Pi}{\partial a \partial \theta}}{\frac{\partial^{2} C S}{\partial t^{2}}+V^{\prime \prime}(a)+\frac{\partial^{2} \Pi}{\partial a^{2}}}
\end{gathered}
$$

Recall that by assumption we have $\partial C S_{i} / \partial t<0, \partial C S_{i} / \partial \theta \geq 0, \partial^{2} C S_{i} / \partial t^{2} \geq 0$, and $\partial^{2} C S_{i} / \partial t \partial \theta \leq$ 0 . The other elements required to sign (13) are $\frac{\partial^{2} \Pi}{\partial a \partial \theta}=-e^{-r a} \pi^{\prime}(\theta)<0$ and $\frac{\partial^{2} \Pi}{\partial a^{2}}=\frac{\partial}{\partial a}\left(-e^{-r a} \pi(\theta)\right)=$ $r e^{-r a} \pi(\theta)>0$. Therefore if $V(a)$ is linear or convex, $d a^{*} / d \theta$ is unambiguously positive. However, 
the more natural assumption would be that $V(a)$ is concave (i.e., that the marginal benefit of delay to the regulator declines as delay increases), and thus the sign of $d a^{*} / d \theta$ is ambiguous in general. If the sign of a marginal change in type is ambiguous, then so is the sign of a discrete change in type from $L$ to $H$. Thus the sign of $a^{L}-a^{H}$ is not known.

Isoprofit curves when fixed costs are constant Here I show that the isoprofit curves in figure 2 must slope down. The slope of an isoprofit curve in $(s, a)$ space is found from (3), which expands to $\Pi_{\text {sum }}=e^{-r s}\left[-F+e^{-r a_{0}} \pi(\theta) / r\right]+\delta\left[-F+e^{-r a} \pi(\theta) / r\right]$ (recall $s_{2}$ is zero in equilibrium). It follows that the slope is $-\frac{\partial \Pi_{s u m}}{\partial s} / \frac{\partial \Pi_{s u m}}{\partial a}=-\frac{\left[e^{-r a 0} \pi(\theta) / r-F\right]}{e^{r(s-a)} \delta \pi(\theta)}$, which is always negative because $\frac{\partial \Pi}{\partial s}<0$ and $\frac{\partial \Pi}{\partial a}<0$. Differentiating the slope with respect to $s$ reveals that the curves are convex:

$$
\frac{d}{d s}\left(-\frac{\partial \Pi_{\text {sum }}}{\partial s} / \frac{\partial \Pi_{\text {sum }}}{\partial a}\right)=r\left(\frac{\partial \Pi_{\text {sum }}}{\partial s} / \frac{\partial \Pi_{\text {sum }}}{\partial a}\right)>0 \text {. }
$$

Conditions for the existence of a separating equilibrium with constant fixed costs If the participation constraint is met, a separating equilibrium always exists when $a^{L}<a^{H}$. Whenever the isoprofit curves of the two types cross, $L$ 's has the flatter slope (a "single-crossing" property). To show this, note that from (14), the slope of an isoprofit curve changes with $\theta$ as

$$
\frac{\partial}{\partial \theta}\left(-\frac{\partial \Pi_{\text {sum }}}{\partial s} / \frac{\partial \Pi_{\text {sum }}}{\partial a}\right)=\left[\frac{e^{-r s}}{\delta e^{-r a} \pi(\theta)}\right]\left(\left[-F+e^{-r a_{0}} \pi(\theta) / r\right] \frac{\pi^{\prime}(\theta)}{\pi(\theta)}-\left[e^{-r a_{0}} \pi^{\prime}(\theta) / r\right]\right)<0
$$

If $\pi$ is a positive function, integrating (15) between $\theta^{L}$ and $\theta^{H}$ shows that the sign of the nonmarginal change between the two types is negative. Thus $H$ has a steeper downward-sloped isoprofit curve than $L$ at every point of crossing. Then the isoprofit curves must be as depicted in Figure 2, and the " $L$ " signal is too costly for type $H$ to send but not too costly for $L$ to send. The incentive constraints are satisfied and a separating equilibrium exists. 
The sign of $d a^{*} / d \theta$ with time-varying fixed costs The derivative of (7) with respect to $\theta$ in this case leads to an expanded expression for $d a^{*} / d \theta$ :

$$
\frac{d a^{*}}{d \theta}=-\frac{\left(\frac{\partial^{2} C S}{\partial t^{2}} \frac{\partial s_{2}^{*}}{\partial \theta}+\frac{\partial^{2} C S}{\partial t \partial \theta}\right)\left(\frac{\partial s_{2}^{*}}{\partial a}+1\right)+\frac{\partial C S}{\partial t} \frac{\partial^{2} s_{2}^{*}}{\partial a \partial \theta}+\frac{\partial^{2} \Pi}{\partial a \partial \theta}}{\frac{\partial^{2} C S}{\partial t^{2}}\left(\frac{\partial s_{2}^{*}}{\partial a}+1\right)\left(\frac{\partial s_{2}^{*}}{\partial a}+1\right)+\frac{\partial C S}{\partial t} \frac{\partial^{2} s_{2}^{*}}{\partial a^{2}}+V^{\prime \prime}(a)+\frac{\partial^{2} \Pi}{\partial a^{2}}}
$$

Given that (13) was of indeterminate sign, it is no surprise that (16) is also indeterminate.

Isoprofit curves with time-varying fixed costs As above, the slope of an isoprofit curve in $(s, a)$ space is $-\left(\partial \Pi_{\text {sum }} / \partial s\right) /\left(\partial \Pi_{\text {sum }} / \partial a\right)=-(\partial \Pi / \partial s) /[\delta(\partial \Pi / \partial a)]$. Since the denominator is negative, the slope is positive to the right of $s_{1}^{*}\left(a_{0}, \theta\right)$ and negative to the left (recall that from (2), $\partial \Pi / \partial s$ evaluated at $s_{1}^{*}\left(a_{0}, \theta\right)$ is zero). Thus the isoprofit curves take a maximum at $s_{1}^{L}$ for $L$ and $s_{1}^{H}$ for $H$, as depicted in figures 2 and 3 . The slope changes with $\theta$ as

$$
\frac{\partial}{\partial \theta}\left(-\frac{\frac{\partial \Pi}{\partial s}}{\delta \frac{\partial \Pi}{\partial a}}\right)=\frac{\frac{\partial \Pi}{\partial s} \frac{\partial^{2} \Pi}{\partial a \partial \theta}}{\delta\left(\frac{\partial \Pi}{\partial a}\right)^{2}}-\frac{\frac{\partial^{2} \Pi}{\partial s \partial \theta}}{\delta \frac{\partial \Pi}{\partial a}}
$$

The signs of the unambiguous pieces are $\frac{\partial \Pi}{\partial a}<0$ (as noted in the proof of Proposition 1 ), $\frac{\partial^{2} \Pi}{\partial a \partial \theta}=$ $-e^{-r(a+s 2)} \pi_{2}^{\prime}<0$, and $\frac{\partial^{2} \Pi}{\partial s \partial \theta}=-e^{-r\left(a_{0}+s\right)} \pi^{\prime}(\theta)<0$. The only term that changes sign with $s$ is $\frac{\partial \Pi}{\partial s}$, which as noted above is positive for $s<s_{1}^{*}\left(a_{0}, \theta\right)$ and negative for $s>s_{1}^{*}\left(a_{0}, \theta\right)$. Thus to the left of $s_{1}^{*}\left(a_{0}, \theta\right),(17)$ is negative, meaning that for a marginal decrease in type from type $H$, the slope gets steeper.

By implication, whenever the isoprofit curves of the two types depicted in Figure 3 cross to the left of $s_{1}^{H}$, then the curve for $H$ is flatter than the curve for $L$. Therefore, any separating equilibrium with $a^{H}>a^{L}$ has $L$ sending a larger signal $s$ than $H$ sends and $s^{L} \geq s_{1}^{L}>s_{1}^{H}$. The case ruled out would have $L$ 's signal lower than $s_{1}^{H}$ (depicted in Figure 6). The only way $L$ 's signal could be lower than $s_{1}^{H}$ is if point $B$ is to the left of point $A$. In that case $L$ 's signal could be between $B$ and $A$. But then there must be a point $E$ where the two isoprofit curves cross, and at $E, H$ 's curve is steeper. Since $E$ must be to the left of $s_{1}^{H}$, the proposition states that the $H$ curve must be flatter, so point $E$ creates a contradiction.

To the right of $s^{*}$, the sign of (17) is ambiguous. 
The single-crossing condition with time-varying fixed costs When $a^{H}<a^{L}$ we want to rule out the (nonintuitive) case in which $H$ signals with a high $s$. To the right of the peaks of the isoprofit curves, the sign of (17) is ambiguous, and $H$ 's curve might cross $L$ 's curve again (see Figure 7). As in the constant fixed cost case, a single-crossing condition rules out this behavior. The single-crossing condition for time-varying fixed costs is essentially the same as (15), with an extra negative term involving the derivative of $F$ on the left side of the inequality. The condition always holds given the assumptions of the model, and thus cases like that depicted in Figure 7 are ruled out. 


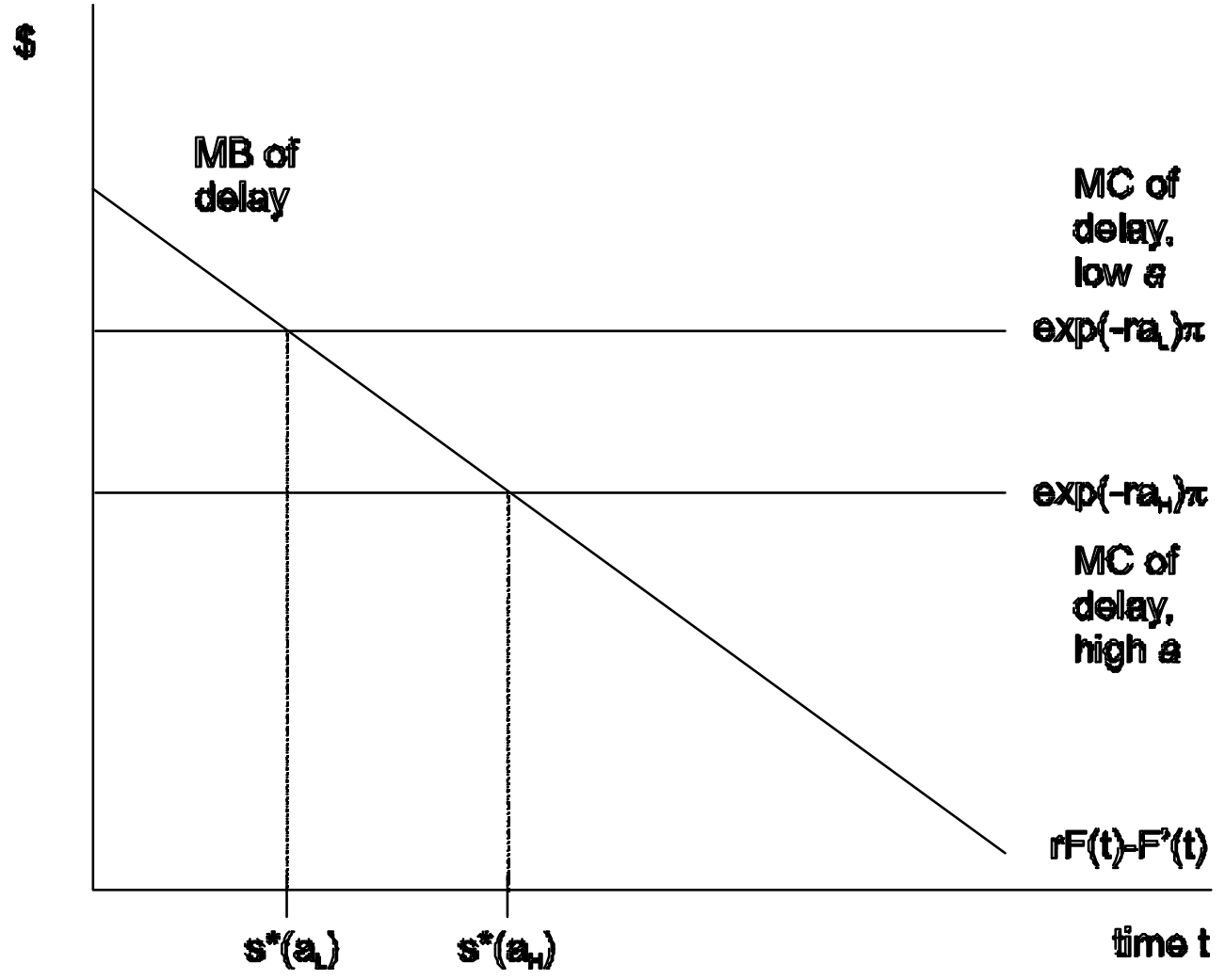

Figure 1: Determination of Optimal Innovation Date 


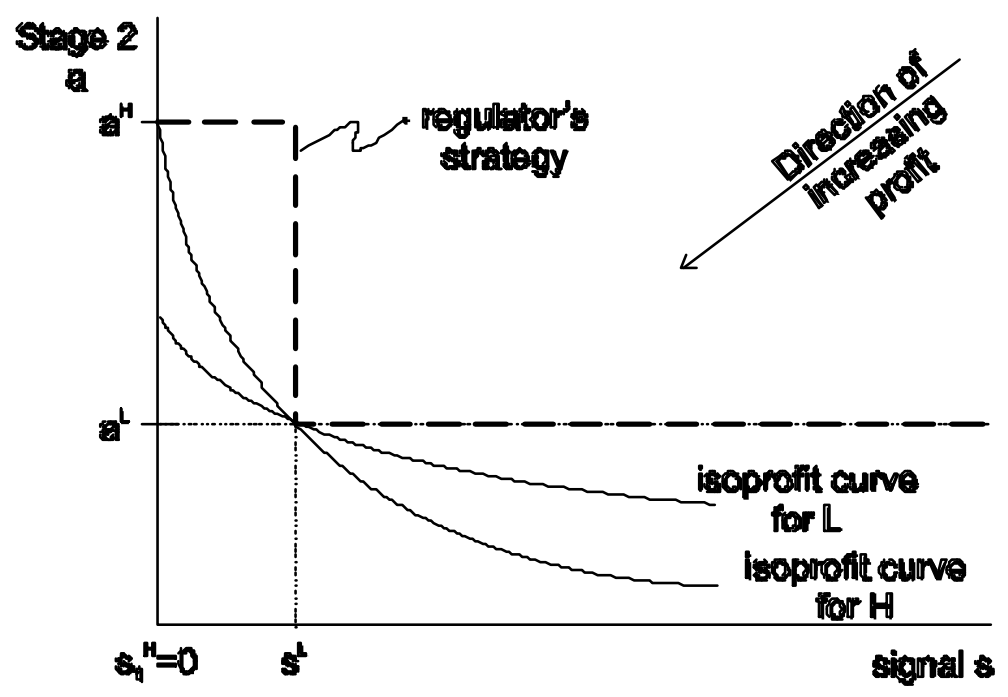

Figure 2: A separating equilibrium when fixed costs are constant and $a^{L}<a^{H}$

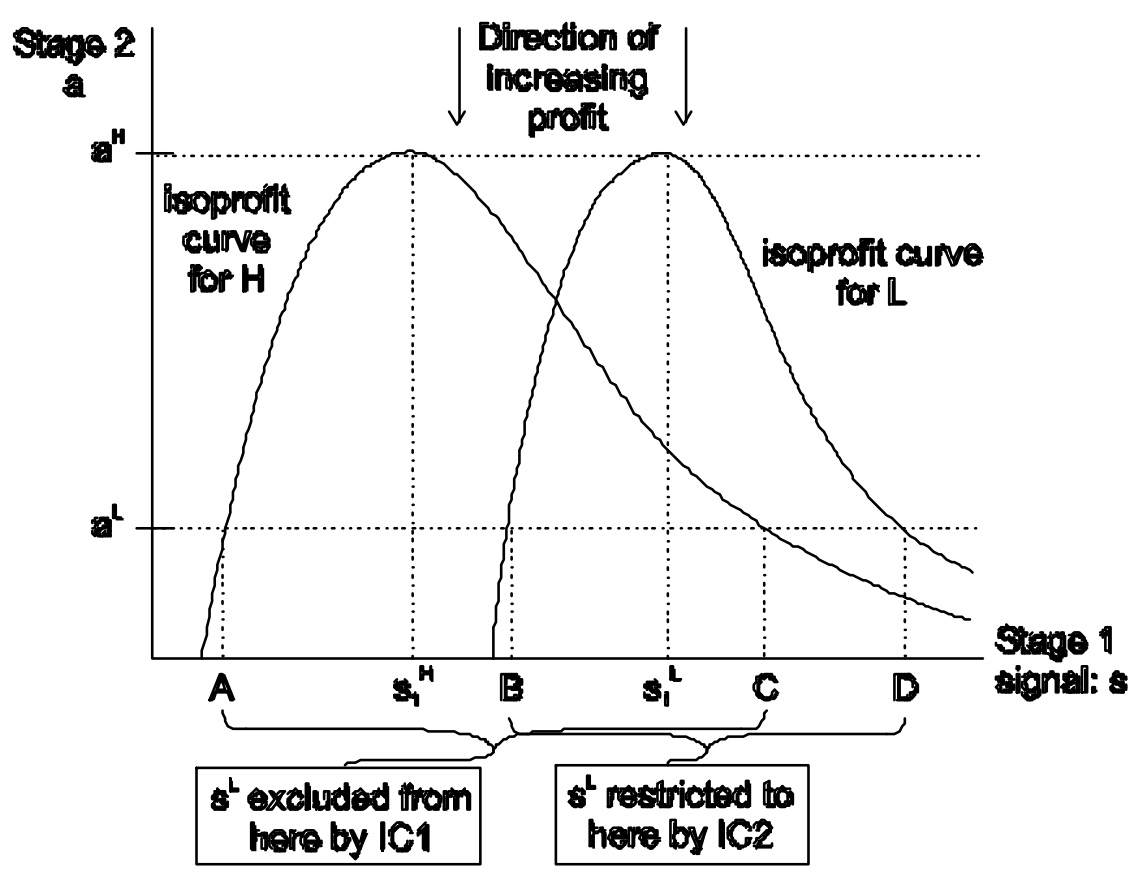

Figure 3: Incentive constraints $\left(a^{L}<a^{H}\right.$ and falling fixed costs) 


\begin{tabular}{cccc}
\hline & Observed Outcomes & Implications from \\
Case & $\Delta s$ & $\Delta a$ & the Signaling Model \\
\hline \hline 1 & - & - & possible for either type \\
2 & + & + & possible for either type \\
3 & + & - & possible only for type $H$ \\
4 & - & + & impossible \\
\hline
\end{tabular}

Table notes: see Proposition 4. These outcomes are based on the model in section 2.3 with decreasing fixed costs.

Table 1: Empirical Predictions from the Signaling Model

\begin{tabular}{|c|c|c|c|c|c|c|c|c|c|c|c|}
\hline \multirow[b]{2}{*}{ State } & \multirow{2}{*}{$\begin{array}{c}\text { Sample } \\
N\end{array}$} & \multicolumn{5}{|c|}{$\begin{array}{c}\text { Innovation Delay } \\
\text { Before Regulatory Change } \\
\text { Stage } 1 \text { (1991-mid 1994) }\end{array}$} & \multicolumn{5}{|c|}{$\begin{array}{c}\text { Innovation Delay } \\
\text { After Regulatory Change } \\
\text { Stage } 2 \text { (mid 1994-1999) }\end{array}$} \\
\hline & & min & mean & median & $\max$ & $N$ & $\min$ & mean & median & $\max$ & $N$ \\
\hline 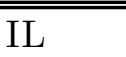 & 95 & "0 & 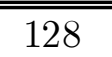 & 34 & ב665 & $\begin{array}{c}34 \\
\end{array}$ & ב0 & 45 & "0 & ב 503 & 62 \\
\hline IN & 77 & 0 & 457 & 199 & 2605 & 29 & 0 & 159 & 45 & 1318 & 48 \\
\hline $\mathrm{OH}$ & 65 & 361 & 1267 & 1235 & 2518 & 8 & 0 & 98 & 26 & 1071 & 62 \\
\hline WI & 106 & 0 & 357 & 150 & 2441 & 40 & 0 & 100 & 18 & 1667 & 66 \\
\hline Total & 349 & & & & & 111 & & & & & 238 \\
\hline
\end{tabular}

Table notes: figures are in days. See text for calculation of $s$.

Table 2: Change in Innovation Delay Between Stages $(\Delta s)$ 


\begin{tabular}{|c|c|c|c|c|c|c|c|c|c|c|c|}
\hline \multirow[b]{2}{*}{ State } & \multirow{2}{*}{$\begin{array}{c}\text { Sample } \\
N \\
\end{array}$} & \multicolumn{5}{|c|}{$\begin{array}{c}\text { Regulatory Delay } \\
\text { Before Regulatory Change } \\
\text { Stage } 1(1991-\text { mid 1994) } \\
\end{array}$} & \multicolumn{5}{|c|}{$\begin{array}{c}\text { Regulatory Delay } \\
\text { After Regulatory Change } \\
\text { Stage } 2 \text { (mid 1994-1999) } \\
\end{array}$} \\
\hline & & $\min$ & mean & median & $\max$ & $N$ & $\min$ & mean & median & $\max$ & $N$ \\
\hline IL & 97 & 1 & 36 & 46 & 48 & 29 & 1 & 30 & 16 & 248 & 68 \\
\hline IN & 69 & 43 & 103 & 83 & 217 & 15 & 1 & 13 & 3 & 152 & 54 \\
\hline WI & 103 & 2 & 106 & 44 & 752 & 25 & 1 & 9 & 10 & 48 & 78 \\
\hline Total & 269 & & & & & & & & & & \\
\hline
\end{tabular}

Table notes: figures are in days. Regulatory delay data are not available for Ohio.

Table 3: Change in Regulatory Delay Between Stages $(\Delta a)$

\begin{tabular}{lccccc}
\hline \multirow{2}{*}{ State } & Period & Mean (s.e.) & Median & $\begin{array}{c}\text { Lower 95\% conf. } \\
\text { limit for median }\end{array}$ & $\begin{array}{c}\text { Upper 95\% conf. } \\
\text { limit for median }\end{array}$ \\
\hline \hline IL & Stage 1 & $126.5(32.4)$ & 32 & 0 & 53 \\
& Stage 2 & $45.0(13.1)$ & 0 & 0 & 0 \\
IN & Stage 1 & $320.7(97.6)$ & 106 & 76 & 221 \\
& Stage 2 & $133.5(38.2)$ & 42 & 28 & 53 \\
OH & Stage 1 & $1413(309)$ & 1493 & 0 & 1493 \\
& Stage 2 & $87.3(23.2)$ & 19 & 13 & 32 \\
WI & Stage 1 & $356.6(81.6)$ & 143 & 77 & 201 \\
& Stage 2 & $99.5(31.4)$ & 19 & 3 & 23 \\
\hline
\end{tabular}

Table notes: figures (in days) are based on survival curve estimates (see Figure 8). Stage 1 is 1991 to mid 1994, Stage 2 is thereafter.

Table 4: Estimated innovation delay $s$ 


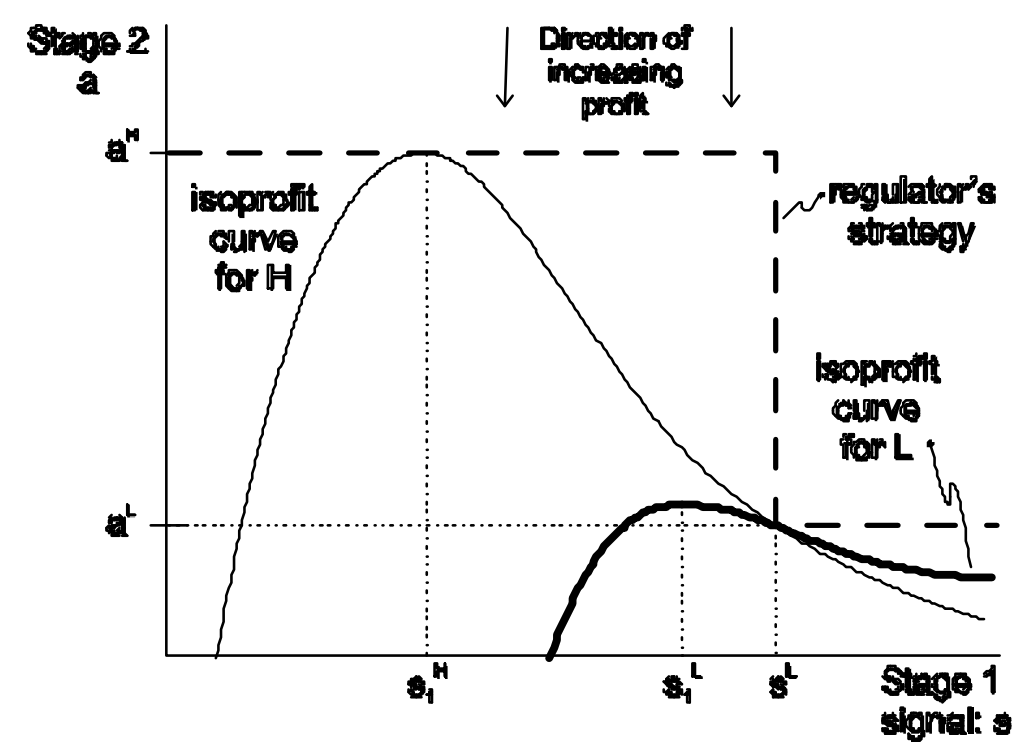

Figure 4: A separating equilibrium $\left(a^{L}<a^{H}\right.$ and falling fixed costs $)$

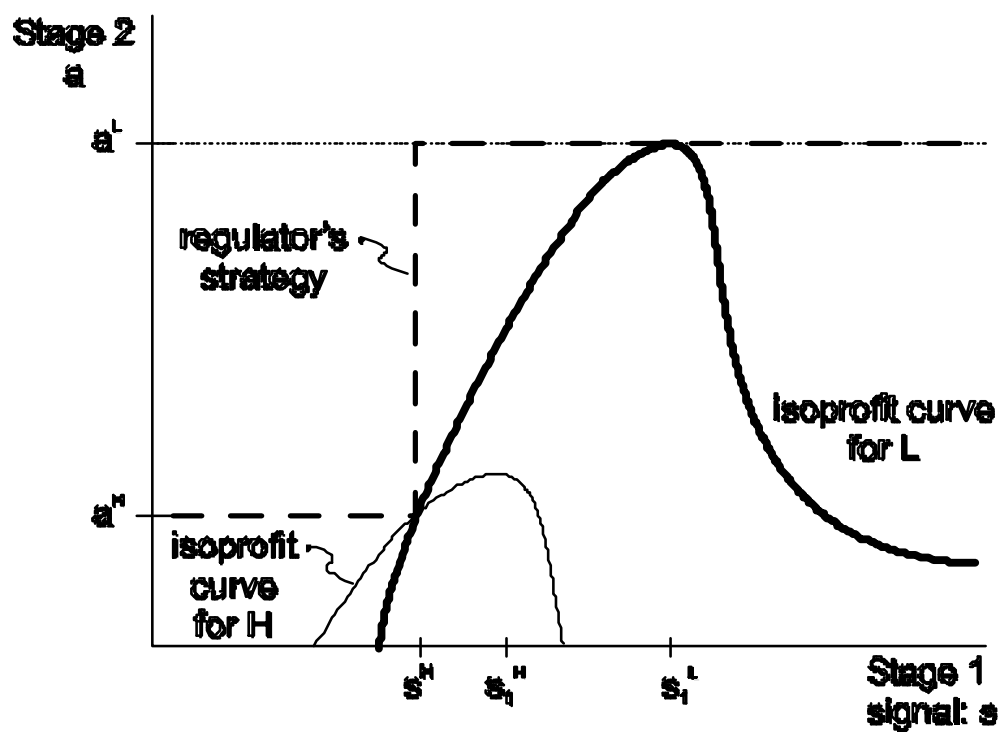

Figure 5: Incentive constraints $\left(a^{H}<a^{L}\right.$, falling fixed costs) 


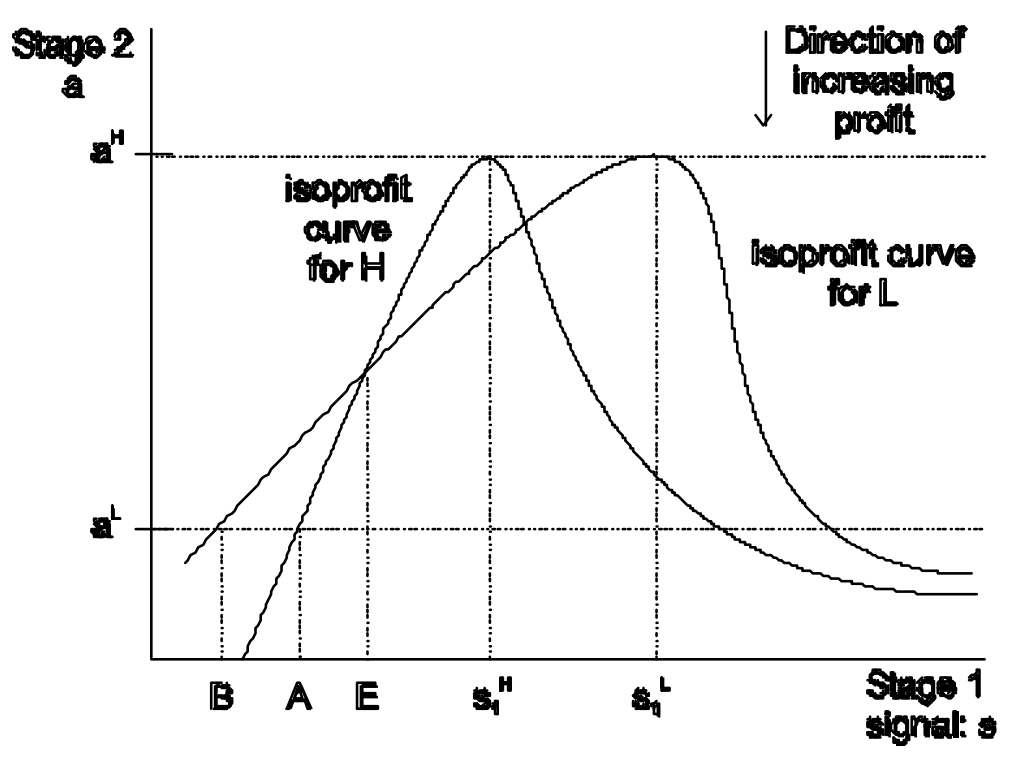

Figure 6: Impossible case for incentive constraints

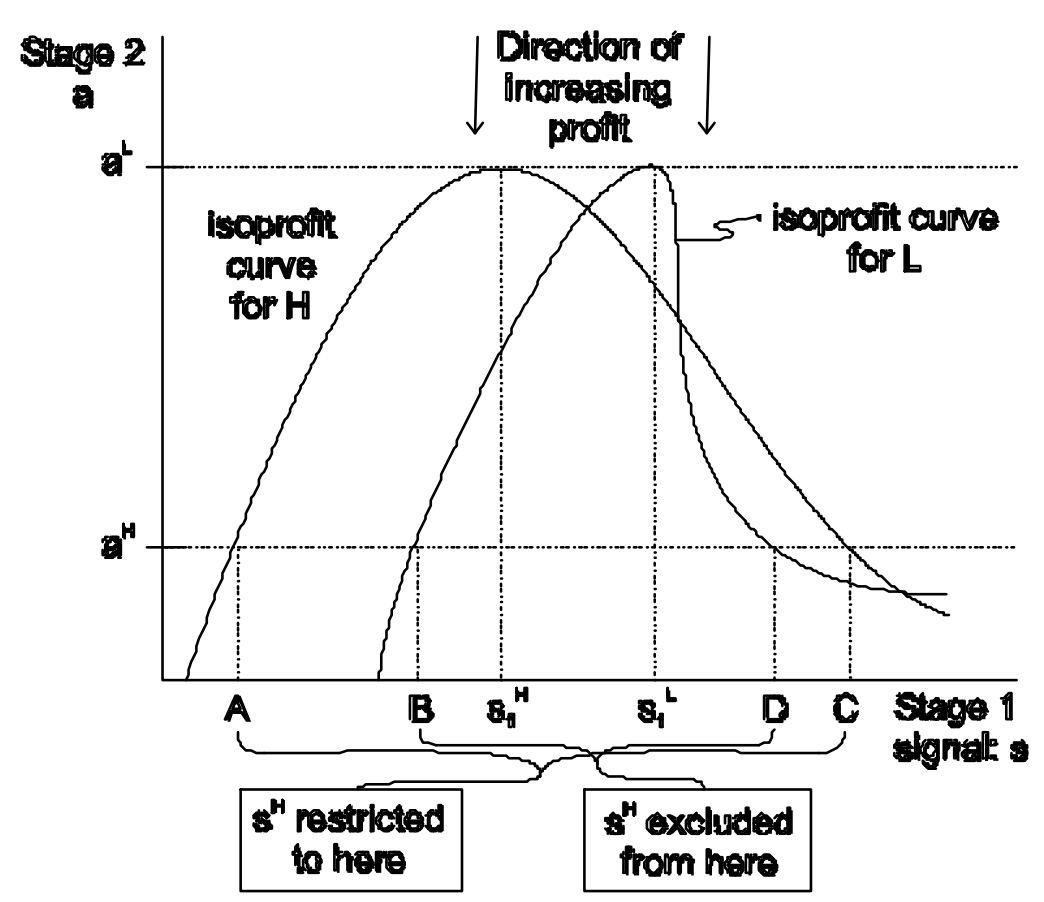

Figure 7: Incentive constraints ruled out by the single-crossing condition 


\section{Illinois}

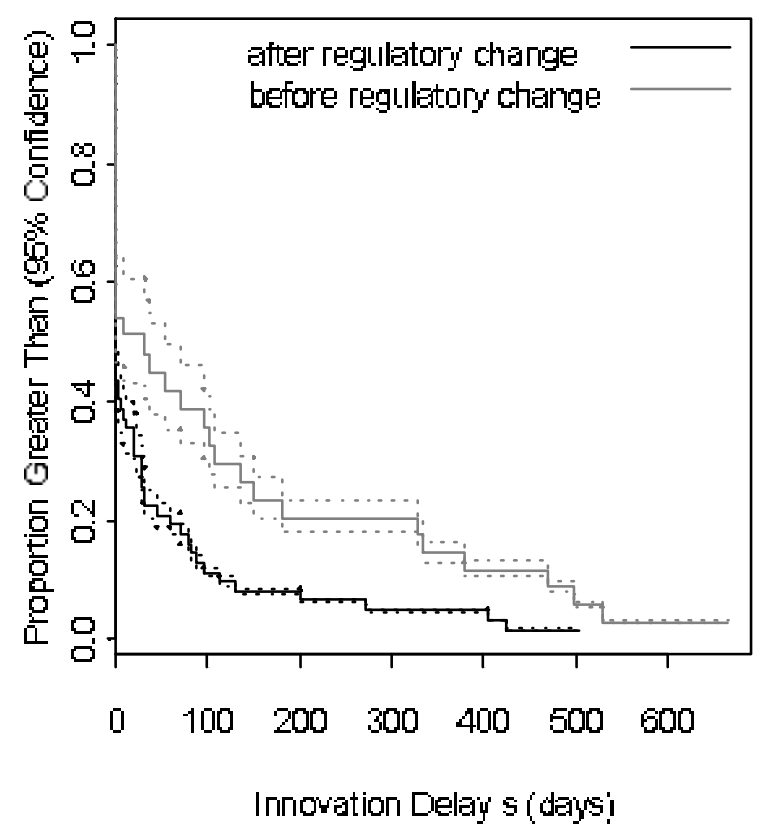

Ohio

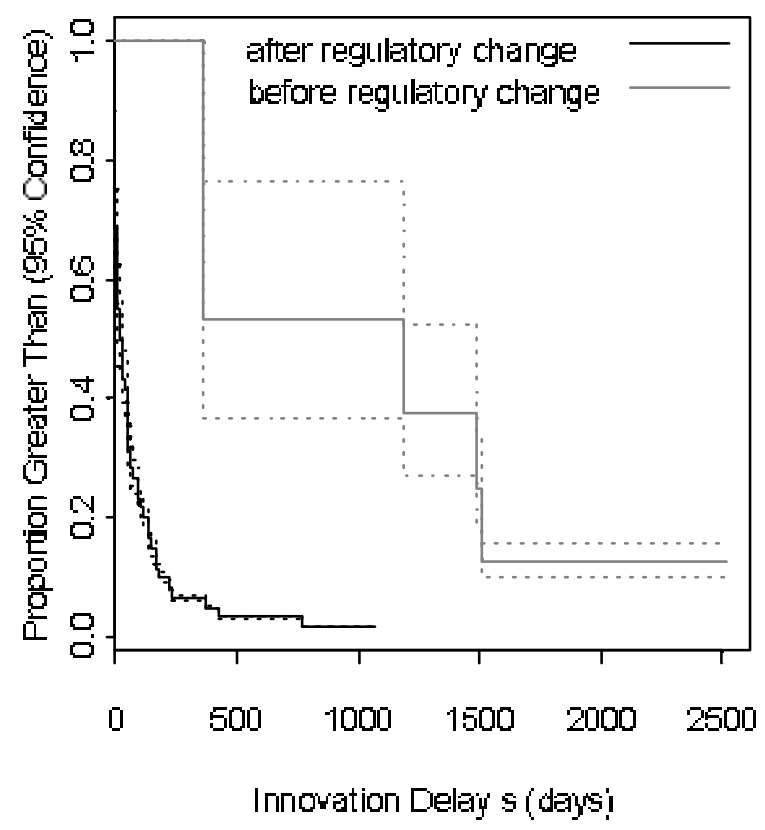

Indiana

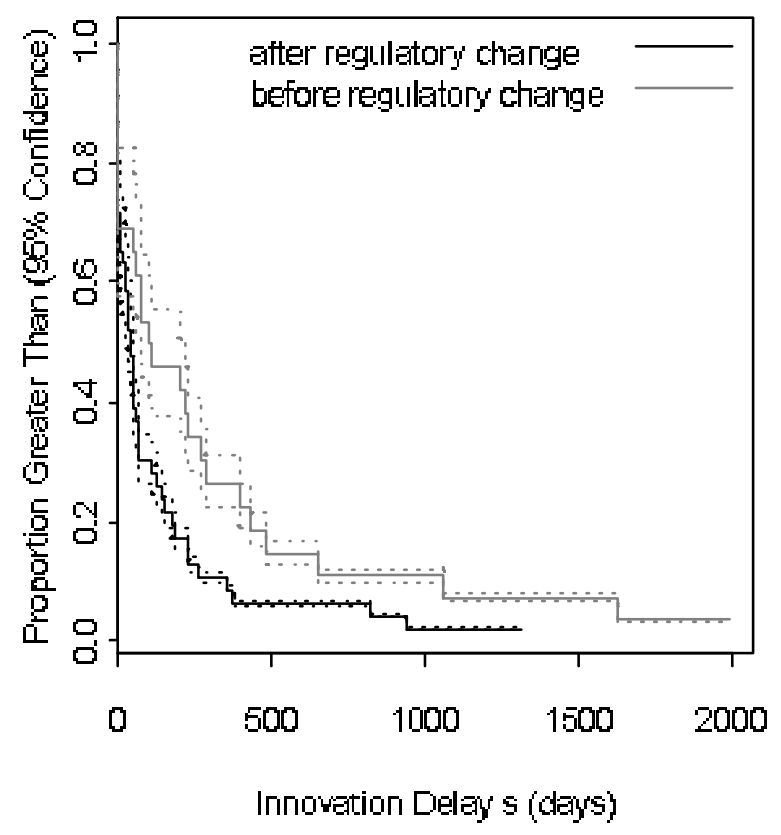

Wisconsin

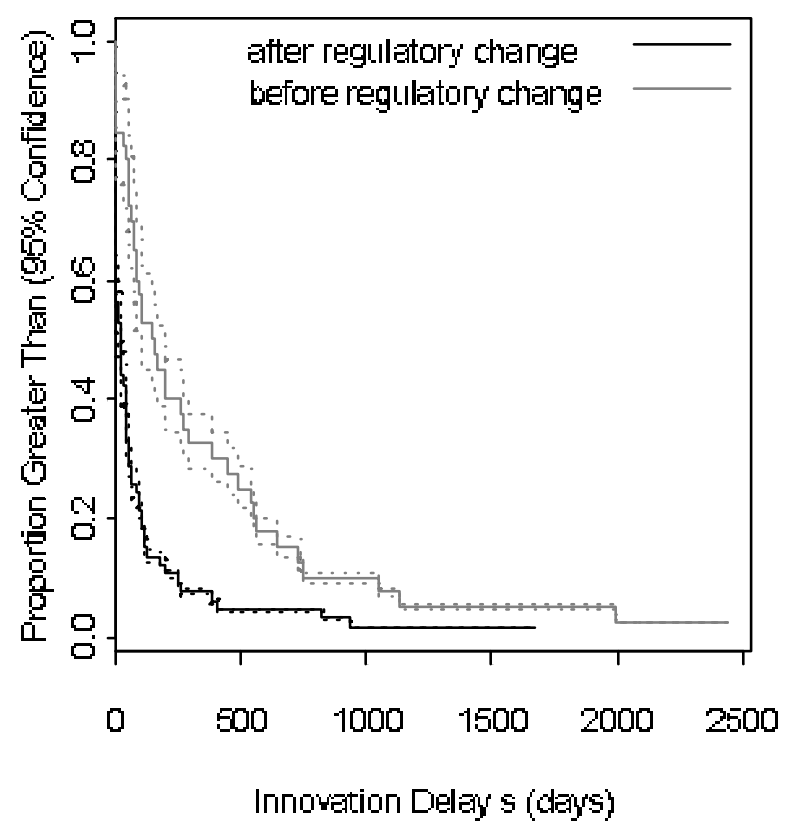

Figure 8: Nonparametric survival curves for innovation delay $s$ 

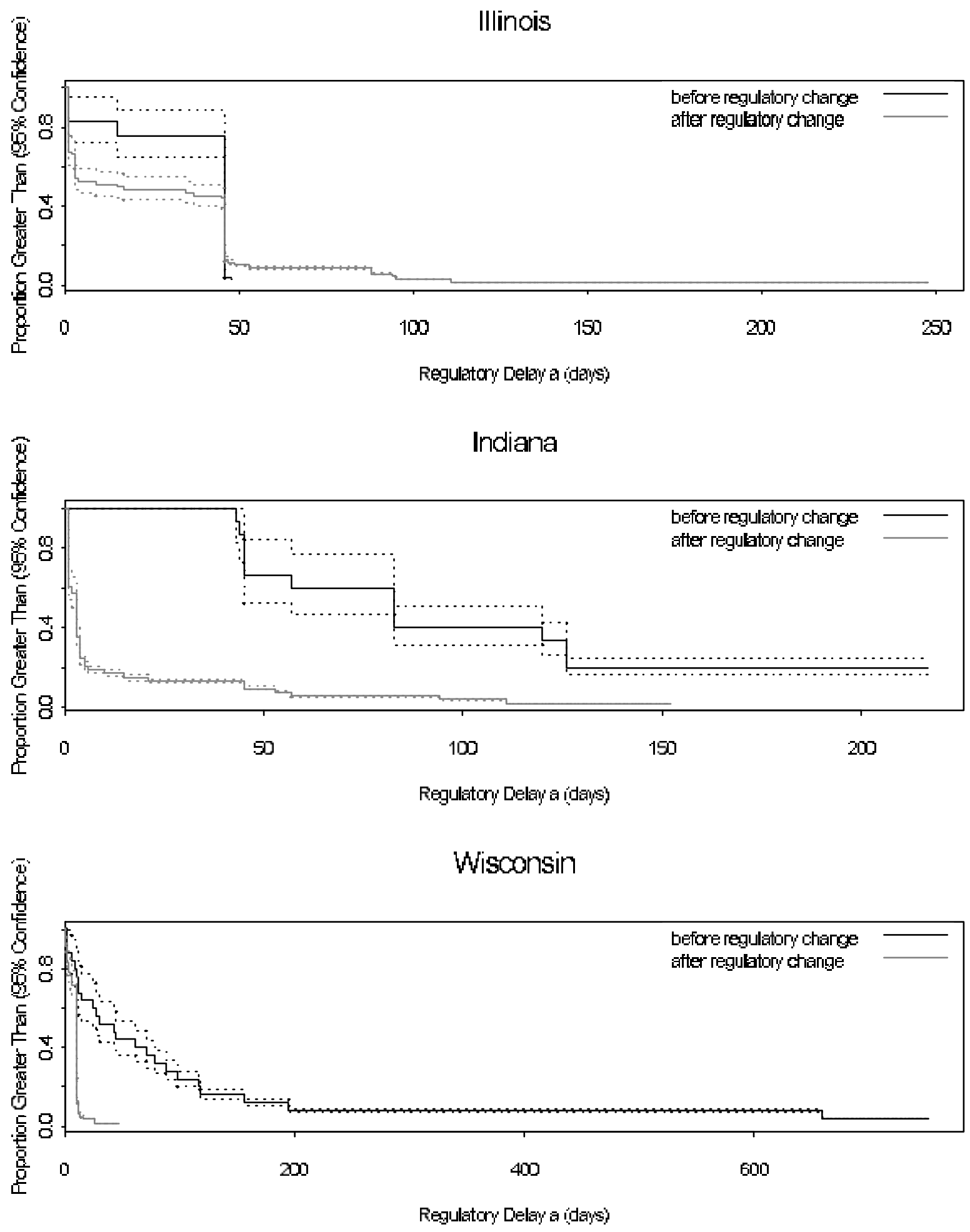

Figure 9: Nonparametric survival curves for regulatory delay $a$ 


\begin{tabular}{|c|c|c|c|c|c|c|}
\hline \multirow[b]{3}{*}{ State } & \multicolumn{6}{|c|}{ Cox Proportional Hazards Models } \\
\hline & \multicolumn{2}{|c|}{ Fixed Effects } & \multicolumn{2}{|c|}{ Covariates } & \multicolumn{2}{|c|}{ Type Estimation } \\
\hline & coef. & s.e. & coef. & s.e. & coef. & s.e. \\
\hline IL:reg change & $-0.365^{*}$ & $\overline{(0.214)}$ & $\overline{-0.024}$ & (0.273) & -0.270 & 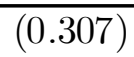 \\
\hline IN:reg change & $-0.727^{* * *}$ & $(0.277)$ & $-0.822^{* * *}$ & $(0.252)$ & $-2.064^{* * *}$ & $(0.461)$ \\
\hline OH:reg change & $-6.360^{* * *}$ & $(0.391)$ & $-0.768^{* * *}$ & $(0.291)$ & $\dagger$ & \\
\hline WI:reg change & $-1.355^{* * *}$ & $(0.220)$ & $-0.722^{* * *}$ & $(0.236)$ & $-2.780^{* * *}$ & $(0.379)$ \\
\hline $\mathrm{IL}$ & $-0.649^{* *}$ & $(0.290)$ & & & -7.131 & $(4.401)$ \\
\hline $\mathrm{OH}$ & $5.551^{* * *}$ & $(0.444)$ & & & $\dagger$ & \\
\hline WI & 0.380 & $(0.318)$ & & & $1.206^{* *}$ & $(0.587)$ \\
\hline FAT & $0.654^{* * *}$ & $(0.137)$ & $0.559^{* * *}$ & $(0.138)$ & $0.641^{* * *}$ & $(0.183)$ \\
\hline PCI & & & $-4.531^{*}$ & $(2.096)$ & $-8.015^{*}$ & $(4.896)$ \\
\hline ACCESS & & & -0.382 & $(0.386)$ & 5.884 & $(4.175)$ \\
\hline DENSITY & & & 0.473 & $(0.401)$ & 1.227 & $(1.051)$ \\
\hline $\mathrm{INDPAT}_{t-1}$ & & & -0.024 & $(0.273)$ & -0.440 & $(0.568)$ \\
\hline EXPDELAY & & & & & $-0.020^{* * *}$ & $(0.003)$ \\
\hline $\mathrm{N}$ & 5 & & & & 3 & \\
\hline Log likelihood & -16 & & -16 & & -11 & \\
\hline
\end{tabular}

$*=10 \%$ level significance ${ }^{* *}=5 \%$ level significance; $* * *=1 \%$ level significance.

$\dagger$ Regulatory delay data are not available for Ohio.

Table notes: The model incorporates time-varying covariates. Larger positive coefficients imply longer delays. Std. errors are adjusted for multiple observations (clustering) from a state and from an individual service across states. The number of observations is apparently higher than in Table 2 only because of the coding of time-varying covariates; the number of actual events underlying both models is the same. Excluded state dummy is Illinois. FAT is an indicator for innovation delays calculated from the initial date the service was filed in the Federal Access Tariff; other delays calculated from the date of the first filing in a state tariff (with first state's delay changed from 0 to 0.5 ). PCI is per capita personal income in the state. ACCESS is the number of access lines of Ameritech's subscribers in the state. DENSITY is the state's population divided by its area. INDPAT $t-1$ is the one-year lagged count of patents approved in the classes relevant to telecommunications services $(359,370,379$, and 395). The constant in the Cox model is absorbed into the unspecified baseline hazard.

Table 5: Semiparametric estimation results for innovation delay $s$ 


\begin{tabular}{lccccc}
\hline State & Period & Mean (s.e.) & Median & $\begin{array}{c}\text { Lower 95\% conf. } \\
\text { limit for median }\end{array}$ & $\begin{array}{c}\text { Upper 95\% conf. } \\
\text { limit for median }\end{array}$ \\
\hline \hline IL & Stage 1 & $36.2(3.3)$ & 46 & 46 & 46 \\
& Stage 2 & $30.1(4.7)$ & 17 & 3 & 45 \\
IN & Stage 1 & $103.4(16.4)$ & 83 & 57 & 120 \\
\multirow{4}{*}{ WI } & Stage 2 & $13.0(4.0)$ & 3 & 3 & 3 \\
& Stage 1 & $105.6(36.9)$ & 44 & 24 & 62 \\
& Stage 2 & $9.5(0.7)$ & 10 & 10 & 10 \\
\hline
\end{tabular}

Table notes: figures (in days) are based on survival curve estimates (see Figure 9). Stage 1 is 1991 to mid 1994, Stage 2 is thereafter. Regulatory delay data are not available for Ohio.

Table 6: Estimated regulation delay $a$

\begin{tabular}{|c|c|c|c|c|}
\hline \multirow[b]{3}{*}{ State } & \multicolumn{4}{|c|}{ Cox Proportional Hazards Model } \\
\hline & \multicolumn{2}{|c|}{ Fixed Effects } & \multicolumn{2}{|c|}{ Covariates } \\
\hline & coef. & s.e. & coef. & s.e. \\
\hline IL:reg change & $-0.278^{*}$ & $(0.163)$ & $\overline{-0.194}$ & $\overline{(0.222)}$ \\
\hline IN:reg change & $-1.750^{* * *}$ & $(0.309)$ & $-1.831^{* * *}$ & $(0.329)$ \\
\hline WI:reg change & $-1.490^{* * *}$ & $(0.266)$ & $-1.419^{* * *}$ & $(0.168)$ \\
\hline IN & $0.801^{* * *}$ & $(0.217)$ & & \\
\hline WI & $0.534^{* *}$ & $(0.265)$ & & \\
\hline PUCBUDGET & & & $-1.348^{* *}$ & $(0.549)$ \\
\hline REPUB & & & 0.070 & $(0.150)$ \\
\hline REPUBH & & & -0.427 & $(0.653)$ \\
\hline $\mathrm{N}$ & \multicolumn{2}{|c|}{299} & \multicolumn{2}{|c|}{299} \\
\hline $\log ($ likelihood $)$ & \multicolumn{2}{|c|}{-1199.7} & \multicolumn{2}{|c|}{-1199.4} \\
\hline
\end{tabular}

$*=10 \%$ level significance $* *=5 \%$ level significance; $* * *=1 \%$ level significance.

Table notes: See notes to Table 5. Regulatory delay data are not available for Ohio. PUCBUDGET is the log budget of the state PUC. REPUB is an indicator for a Republican governor and Republican majority in both houses of the state legislature. REPUBH is the average value of REPUB from 1984 to the previous year.

Table 7: Semiparametric estimation results for regulatory delay $a$ 